\title{
PELATIHAN MENJADI ENTERPRENEUR MELALUI KONSEP PROGRAM LINEAR DAN SOFTWARE WOLFRAM MATHEMATICA
}

\section{TRAINING TO ENTERPRENEUR THROUGH THE CONCEPT OF LINEAR PROGRAMS AND WOLFRAM MATHEMATICA SOFTWARE}

\author{
Yoni Sunaryo*, Ida Nuraida \\ Universitas Galuh, Jln. R. E. Martadinata No. 150 Ciamis \\ *Email: sunaryoyoni@gmail.com \\ (Diterima 09-03-2020; Disetujui 25-03-2020)
}

\begin{abstract}
ABSTRAK
Tujuan dari kegiatan pengabdian ini adalah membentuk karakter seorang entrepreneur pada siswa di SMA N 1 Baregbeg; materi program linear dipraktikkan di lapangan sehingga siswa dapat mengetahui dan merasakan aplikasinya dalam kehidupan nyata; dan mengajarkan pada siswa software wolfram mathematica dan penggunaannya pada materi Program Linear. Kegiatan pengabdian ini pada pelaksanaannya dibagi menjadi beberapa tahapan, yaitu: tahap 1 yang pada kegiatannya pada tahap ini adalah mengumpulkan siswa sebanyak enam orang dari kelas XI. Tahap 2 yaitu pemberian penyuluhan mengenai pentingnya membangun jiwa seorang enterprenur dalam diri mereka mengingat persaingan kerja di zaman sekarang begitu ketat. Materi penyuluhan juga membahas mengenai konsep/materi Program Linear. Tahap 3 yaitu melakukan pembinaan atau bimbingan dalam menyelesaikan konsep Program Linear dengan menggunakan software wolfram mathematica. Kesimpulan kegiatan ini bahwa siswa merasakan banyak manfaat dari kegiatan penyuluhan yang telah dilaksanakan, siswa termotivasi untuk berwirausaha dan terbantu dalam penguasaan terhadap materi Program Linear. Rekomendasi untuk pengabdi selanjutnya yaitu menggunakan software yang dapat dimanfaatkan sebagai alat bantu siswa dalam menguasai materi pelajaran yang ada di sekolah, sekaligus memotivasi siswa untuk memiliki bekal keterampilan hidup yang kelak dapat dimanfaatkan siswa.
\end{abstract}

Kata kunci: Enterpreneur, Program Linear, Software wolfram mathematica

\begin{abstract}
The purpose of this service activity is to shape the character of an entrepreneur in students at SMA N 1 Baregbeg; linear program material is practiced in the field so students can know and feel its application in real life; and teach students the tungsten mathematica software and its use in the Linear Program material. The service activities are carried out in several stages, namely: stage 1 which at this stage is to gather as many as six students. These students were taken from class XI. Stage 2 which in its activities at this stage is that students are given counseling about the importance of building the spirit of an entrepreneur in themselves given the current competitive workplace. Extension material also discusses the concept / material of the Linear Program. Stage 3 which in its activities carried out at this stage is that the student gets coaching or guidance in completing the Linear Program concept by using the tungsten mathematica software. The conclusion of this activity is that students feel a lot of benefits from the counseling activities that have been carried out, students are motivated to become entrepreneurs and are helped in mastering the Linear Program material. The recommendation for the next servant is to use software that can be used as a tool for students to master the subject matter at school while motivating students to have the provision of life skills that can later be utilized by students.
\end{abstract}

Keywords: Entrepreneur, Linear Program, Wolfram mathematica software

\section{PENDAHULUAN}

Sekolah merupakan tempat menimba ilmu yang berbentuk lembaga formal yang di dalamnya terdapat berbagai kegiatan salah satunya kegiatan belajar mengajar. Pada kegiatan belajar mengajar, siswa diajarkan beberapa mata pelajaran salah satunya mata pelajaran Matematika. Matematika sangat kental dengan aktifitas sehari-hari siswa meski terkadang tak 
dapat langsung terlihat manfaatnya padahal semua materi matematika memiliki korelasi dengan peristiwa-peristiwa dalam dunia nyata.

Materi matematika yang dapat langsung diaplikasikan oleh siswa pada kehidupan nyata salah satunya adalah materi Program Linear. Materi ini dapat digunakan dalam mencari nilai optimasi atau optimum. Jika dikaitkan dengan dunia wirausaha, maka materi ini akan sangat membantu siswa dalam mencari strategi yang tepat untuk mendapatkan keuntungan maksimal dan pembiayaan minimal suatu produksi. Dengan menguasai konsep Program Linear maka siswa akan sangat terbantu ketika terjun ke dunia wirausaha.

Menurut Sunaryo dan Nuraida (2018), kemajuan teknologi sudah merambah ke dunia pendidikan dan sangat mendukung terhadap peningkatan kualitas pembelajaran. Hal ini ditandai dengan bermunculannya software-software yang berfungsi sebagai alat bantu dalam menguasai materi matematika salah satunya adalah software wolfram mathematica. Software ini dipilih karena berkaitan erat dengan materi Program Linear. Penggunaan software ini pada materi Program Linear dapat membantu siswa dalam memperoleh visualisasi berupa grafik dari suatu sistem pertidaksamaan linear dua variabel. Selain itu, dapat pula diperoleh nilai optimasi suatu permasalahan wirausaha yang merupakan output dari hasil perhitungan yang mana merupakan solusi terbaik dalam menerapkan pinsip ekonomi yaitu "Memperoleh keutungan sebesar-besarnya dan mengeluarkan modal sekecil-kecilnya”.

Berdasarkan hasil keterangan yang diperoleh dari guru matematika di Sekolah Menengah Atas (SMA) N 1 Baregbeg ternyata selama ini pembahasan materi Program Linear tidak disertai dengan penggunaan software wolfram mathematica. Guru menerangkan materi ini sebatas memberi soal cerita kemudian siswa menyelesaikan soal cerita tersebut dengan konsep Program Linear. Tidak ada penggunaan aplikasi komputer yang sepatutnya diajarkan pada siswa agar mampu mengikuti perkembangan IPTEK sehingga siswa dapat berkompetisi di era globalisasi ini.

Siswa yang termasuk klasifikasi prasejahtera merupakan siswa yang perlu mendapat perhatian lebih dalam pembentukan jiwa enteurpreneur mengingat latar belakang ekonomi keluarganya kurang mendukung terhadap keberlanjutan pendidikan mereka pada jenjang pendidikan selanjutnya. Agar siswa tersebut dapat mandiri secara ekonomi minimal dapat membantu ekonomi keluarganya maka perlu adanya pembentukan karakter seorang entrepreneur dalam diri siswa sejak dini. Hasil wawancara menunjukkan bahwa mitra dalam hal ini SMA N 1 Baregbeg belum melakukan pembentukan karakter tersebut.

Menurut Schumpeter dalam Bygrave (1994), wirausaha atau entrepreneur adalah orang yang mendobrak sistem ekonomi dengan memperkenalkan barang dan jasa yang baru, dengan 
menciptakan atau mengolah bahan baku baru. Orang tersebut melakukan kegiatannya melalui organisasi bisnis yang baru ataupun bisa pula dilakukan dalam organisasi bisnis yang sudah ada. Berdasarkan pemaparan tersebut oleh karenanya perlu ada pembahasan tentang entrepreneur para siswa agar mengenal dunia bisnis atau dunia wirausaha sejak dini.

\section{BAHAN DAN METODE}

Terdapat tiga permasalahan utama yang dimiliki oleh mitra, yaitu siswa belum mendapat pembentukan karakter menjadi entrepreneur, materi program linear tidak diperdalam sehingga siswa hanya mengenalnya sebagai konsep saja tanpa tahu aplikasinya dalam kehidupan nyata, dan tidak adanya aplikasi komputer berupa software yang ikut diajarkan pada materi Program Linear padahal ada software yang tepat untuk diajarkan bersamaan dengan materi tersebut yakni software wolfram mathematica.

Dalam rangka menyelesaikan masalah yang dihadapi mitra maka pada kegiatan pengabdian ini diadakan pelatihan dan pembinaan pada siswa khususnya kelas XI dengan jumlah sebanyak enam orang siswa. Keenam orang siswa ini merupakan kader yang akan diberikan penyuluhan mengenai pentingnya membangun jiwa entrepreneur di era globalisasi. Selain itu, diajarkan juga penerapan konsep Program Linear dalam permasalahan dunia usaha. Guna mengimbangi kemajuan perkembangan IPTEK agar siswa memiliki pengetahuan dan keterampilan dalam menggunakan aplikasi komputer, maka kepada mereka diajarkan cara menggunakan software wolfram mathematica. Siswa-siswa tersebut mengangkat kasus wirausaha dan menyelesaikannya dengan menggunakan software wolfram mathematica.

Mengacu pada kerangka permasalahan yang telah dipaparkan, maka kegiatan pengabdian ini pada pelaksanaannya dibagi menjadi beberapa tahapan, yaitu:

Tahap 1

Kegiatan pada tahap ini adalah mengumpulkan siswa sebanyak enam orang yang termasuk pada kriteria yakni siswa yang menerima bantuan dana melalui sekolah. Siswa tersebut diambil dari kelas XI.

Tahap 2

Kegiatan pada tahap ini adalah siswa diberi penyuluhan mengenai pentingnya membangun jiwa seorang enterprenur dalam diri mereka mengingat persaingan kerja di zaman sekarang begitu ketat. Materi penyuluhan juga membahas mengenai konsep/materi Program Linear. 
Pelatihan Menjadi Enterpreneur Melalui Konsep Program Linear dan Software Wolfram Mathematica

Yoni Sunaryo, Ida Nuraida

Tahap 3

Kegiatan yang dilakukan pada tahap ini adalah siswa tersebut mendapat pembinaan atau bimbingan dalam menyelesaikan konsep Program Linear dengan menggunakan software wolfram mathematica.

Mitra kegiatan pengabdian ini adalah SMA N 1 Baregbeg yang berlokasi di dekat kampus Universitas Galuh Ciamis yakni J1. R.E. Martadinata No. 150. Fokus utamanya adalah siswa kelas XI. Mengingat berbagai keterbatasan yang dimiliki tim pengabdian maka siswa kelas XI hanya dipilih sebanyak enam orang sebagai kader/perwakilan. Kader yang terpilih memiliki tugas menularkan dan membagikan pengetahuan dan pengalaman mereka kepada siswa lain, tak terkecuali siswa mampu. Kegiatan pengabdian dilaksanakan pada hari Jumat, 15 Maret tahun 2019 dan Kamis, 21 Maret tahun 2019.

Metode yang dilakukan pada pengabdian ini adalah metode intruksional yang diikuti dengan praktek lapangan. Oleh karena itu, dilakukan terlebih dahulu penyuluhan pada kader mengenai membangun jiwa seorang entrepreneur dan penggunaan software wolfram mathematica pada konsep Program Linear yang mengangkat kasus-kasus nyata dunia usaha. Pada kegiatan praktiknya, kader menyelesaikan sendiri soal-soal yang berkaitan dengan dunia usaha dengan menggunakan software wolfram mathematica.

\section{HASIL DAN PEMBAHASAN}

Kegiatan pengabdian ini dilaksanakan pada bulan Januari sampai bulan April tahun 2019. Kegiatan penyuluhan ini terdiri atas dua tahapan, yaitu penyuluhan mengenai membentuk jiwa entrepreneur dan pembahasan mengenai konsep program linear. Pada kegiatan ini siswa diberi pengarahan pengenai pentingnya berwirausaha dengan melakukan produksi barang guna meringankan beban orang tua agar orang tua tidak terbebani dengan kebutuhan biaya sekolah siswa. Penyuluhan pertama dilaksanakan pada hari Jumat, 15 Maret tahun 2019. Berikut situasi dari kegiatan pada penyuluhan pertama disajikan pada Gambar 1, 2 dan 3.

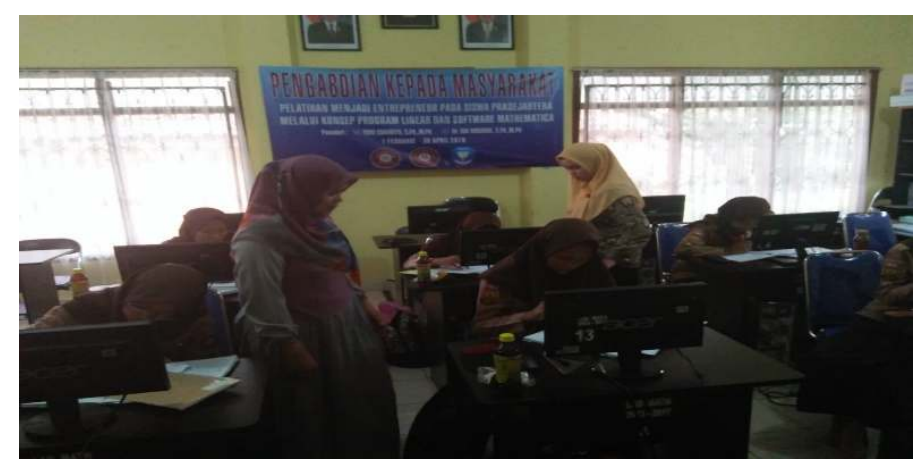

Gambar 1. Siswa Menerima Materi Penyuluhan tentang Entrepreneur 


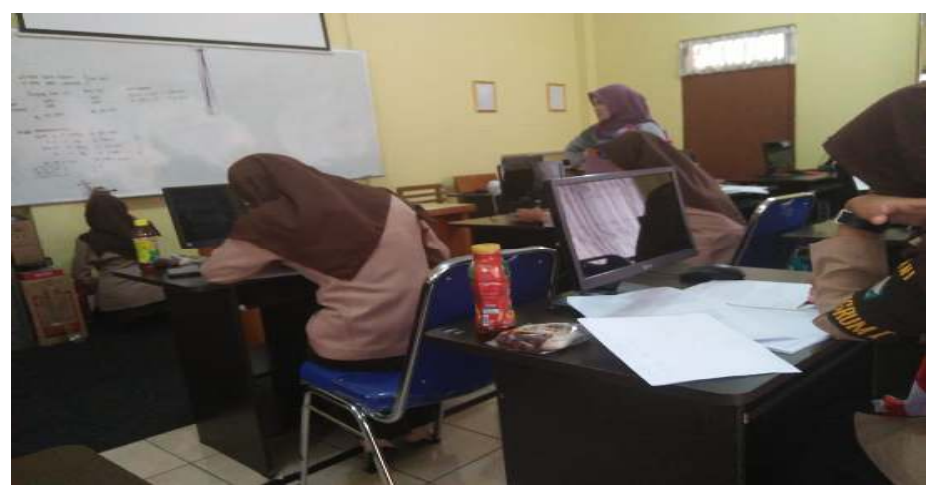

Gambar 2. Pembahasan Mengenai Program Linear

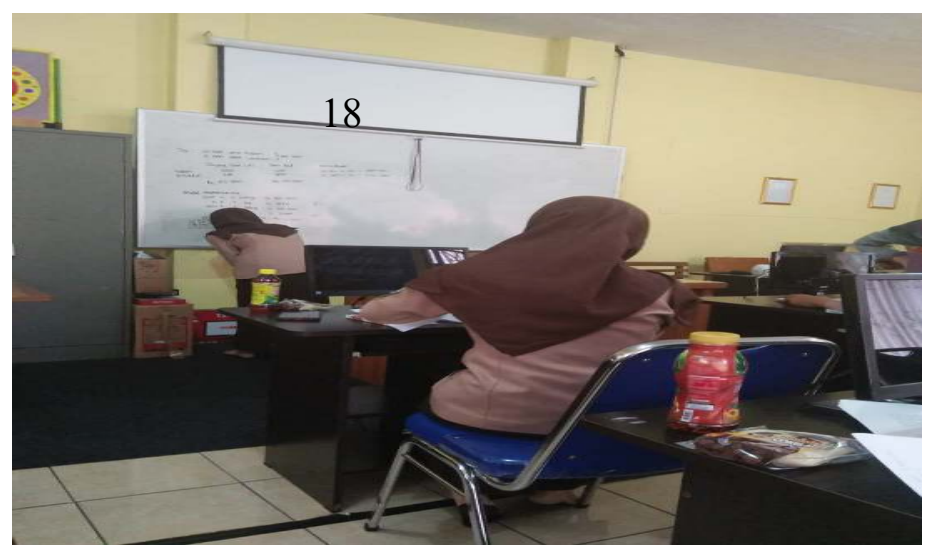

\section{Gambar 3. Siswa Menyelesaikan Permasalahan Program Linear}

Selama kegiatan penyuluhan siswa terlihat antusias dan semangat menyimak materi yang diberikan, baik oleh pemateri I dan pemateri II. Siswa juga mengikuti kegiatan dari awal sampai akhir dengan aktif.

Siswa menerima materi mengenai entrepreneur. Materi yang dibahas adalah sebagai berikut:

\section{- Pengertian Enterpreneur}

Wirausaha secara umum adalah seorang yang berani berusaha secara mandiri dengan mengerahkan segala sumber daya dan upaya meliputi kepandaian mengenali produk baru, menentukan cara produksi baru, menyusun operasi untuk menciptakan sebuah peluang usaha, pengadaan produk baru, memasarkannya, serta mengatur permodalan operasinya untuk menghasilkan sesuatu yang bernilai lebih tinggi, dengan segala risiko yang akan dihadapinya. Dalam prosesnya, wirausahawan mengkombinasikan faktor-faktor produksi seperti sumber daya alam, tenaga kerja, material dan peralatan lainnya, serta melakukan sebuah proses yang disebut creative destruction (pengrusakan yang kreatif) untuk menghasilkan suatu nilai tambah (added value) guna menghasilkan nilai yang lebih tinggi, sehingga inti dari keterampilan wirausaha adalah kreativitas (the core of entrepreneurial skill is creativity). 


\section{- Manfaat Kewirausahaan}

Kewirausahaan berhubungan dengan usaha manusia meningkatkan nilai kehidupan, menciptakan suatu nilai yang baru, berbeda dan peningkatan kehidupan masyarakat. Kewirausahaan memiliki arti penting bagi individu (mikro) dan kehidupan masyarakat. Secara mikro fungsi kewirausahaan dapat berfungsi sebagai planner dan innovator. Planner atau perencanaan yang baik adalah akumulasi dari pengalaman dan pendidikan wirausaha selama menjalankan kegiatan usaha yang selalu berubah. Pengalaman selama beberapa waktu membuat wirausaha memiliki kemampuan untuk merencanakan segala aktivitas bisnis dengan lebih baik, terstruktur, sistematik dan terukur. Fungsi inovator atau keinovasian adalah kemampuan wirausaha untuk melakukan perubahan terus menerus terhadap aktivitas bisnis sesuai kemajuan dan perkembangan jaman. Sifat inovasi muncul berdasarkan pengalaman selama beberapa waktu dari kemampuan wirausaha melihat, mendengar, bertanya dan melakukan perubahan kehidupan bisnis. Fungsi secara makro berhubungan dengan peran kewirausahaan dalam meningkatkan nilai kehidupan atau kemakmuran masyarakat, penggerak, pengendali dan pemakai perkembangan ekonomi suatu bangsa. Bahkan pemerintah melalui peraturan, kebijakan berusaha untuk meningkatkan kewirausahaan untuk mempercepat kemakmuran bangsa.

Selanjutnya siswa menerima materi mengenai Program Linear. Materi yang dibahas adalah sebagai berikut:

1. Program linear merupakan salah satu teknik penelitian operasional yang digunakan paling luas dan diketahui dengan baik, serta berupa metode matematik, yang berfungsi mengalokasikan sumber daya yang langka untuk mencapai tujuan tunggal seperti memaksimumkan keuntungan atau meminimumkan biaya. Program linear banyak diterapkan dalam membantu menyelesaikan masalah ekonomi, industri, militer, dan sosial. Program linier berkaitan dengan penjelasan suatu dunia nyata sebagai suatu model matematik yang terdiri atas sebuah fungsi tujuan dan sistem kendala linier.

2. Program linear digunakan untuk memecahkan masalah pengoptimalan (memaksimalkan atau meminimalkan suatu tujuan). Dari sini program linear dapat digunakan untuk menyelesaikan masalah-masalah manusia. Dalam kehidupan sehari-hari tentu banyak masalah yang berkaitan dengan perhitungan, seperti dalam berdagang. Dalam berdagang seorang pedagang pasti ingin mendapat keuntungan atau laba yang besar/maksimum, maka program linear dapat digunakan untuk menghitung maksimum laba yang bisa diperoleh seorang pedagang.

Contoh persoalan yang dapat diselesaikan dengan menggunakan konsep program linear: 
Tanah seluas $10.000 \mathrm{~m}^{2}$ akan dibangun rumah tipe A dan tipe B. Untuk rumah tipe A diperlukan $100 \mathrm{~m}^{2}$ dan tipe $\mathrm{B}$ diperlukan $75 \mathrm{~m}^{2}$. Jumlah rumah yang dibangun paling banyak 125 unit. Keuntungan rumah tipe A adalah Rp 6.000.000,00/unit dan tipe B adalah Rp 4.000.000,00/unit. Keuntungan maksimum yang dapat diperoleh dari penjualan rumah tersebut adalah ........ Penyelesaian:

Misalnya:

$$
\begin{aligned}
& x=\text { rumah tipe } A \\
& y=\text { rumah tipe } B \\
& 100 x+75 y \leq 10.000 \text { dibagi } 25 \Rightarrow \\
& 4 x+3 y \leq 400 \ldots . .(1) \\
& x+y \leq 125 \ldots . .(2)
\end{aligned}
$$

Keuntungan maksimum : $6000.000 x+4000.000 y=\ldots$ ?

Mencari keuntungan maksimum dengan mencari titik-titik pojok dengan menggunakan sketsa grafik:

Grafik 1 :

$4 x+3 y \leq 400$

titik potong dengan sumbu $X$ jika $y=0$ maka $x=\frac{400}{4}=100$

Titik potongnya $(100,0)$

Titik potong dengan sumbu $Y$ jika $x=0$ maka $y=\frac{400}{3}=133,3$

Titik potongnya $(0,133,3)$

\section{Grafik 2 :}

$x+y \leq 125$

titik potong dengan sumbu $X$ jika $y=0$ maka $x=125$

Titik potongnya $(125,0)$

Titik potong dengan sumbu $Y$ jika $x=0$ maka $y=15$

Titik potongnya $(0,125)$

Gambar grafiknya: 


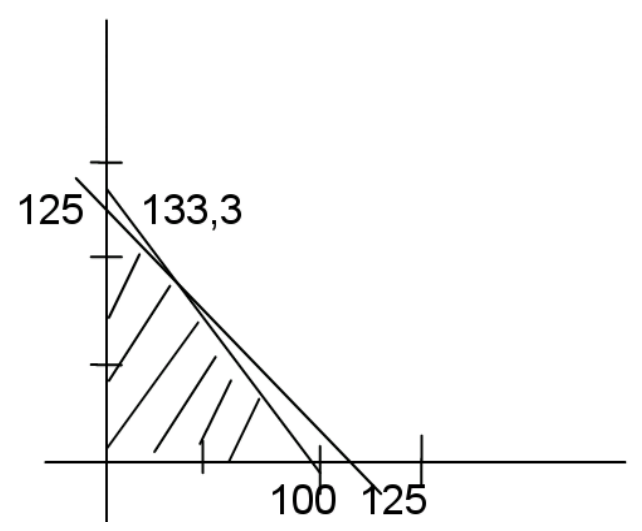

titik potong :

$$
\begin{aligned}
& \text { eliminasi } x \\
& \begin{aligned}
4 x+3 y=400 \times 1 \Rightarrow 4 x+3 y=400 \\
x+y=125 \times 4 \Rightarrow 4 x+4 y=500
\end{aligned} \\
& \begin{aligned}
-y=-100 \\
y=100
\end{aligned} \\
& x+y=125 \\
& x=125-y \\
& =125-100=25 \rightarrow \text { didapat titik potong }(25,100)
\end{aligned}
$$

$\begin{array}{lc}\text { Titik pojok } & 6000.000 x+4000.000 y \\ (100,0) & 600.000 .000 \\ (0,125) & 500.000 .000 \\ (25,100) & 150.000 .000+400.000 .000=550.000 .000\end{array}$

\section{Keuntungan maksimum adalah Rp.600.000.000}

Setelah siswa menerima materi pada penyuluhan yang pertama selanjutnya siswa menerima materi pada penyuluhan kedua yang dilaksanakan pada hari Kamis, 21 Maret tahun 2019. Penyuluhan kedua membahas mengenai penyelesaian persolan Program Linear dengan menggunakan software wolfram mathematica. Siswa diperkenalkan pada tools yang ada pada software wolfram mathematica beserta cara penggunaannya. Melalui pembelajaran mengenai penggunaan software ini siswa menjadi tahu adanya fasilitas dalam menyelesaikan soal Program Linear berupa software wolfram mathematica. Berikut situasi dari kegiatan pada penyuluhan kedua disajikan pada Gambar 4 dan 5. 


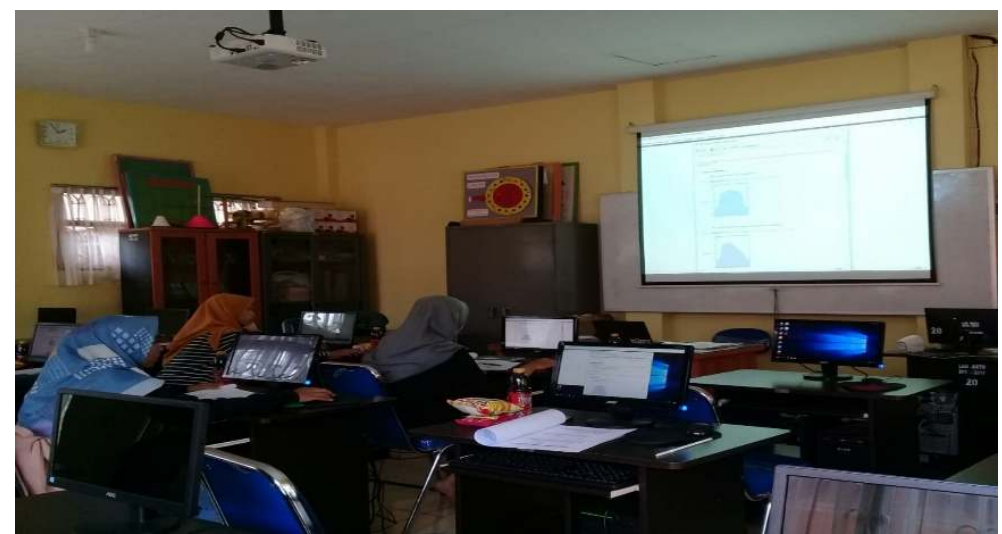

Gambar 4. Pembahasan Mengenai Software waolfram software wolfram mathematica

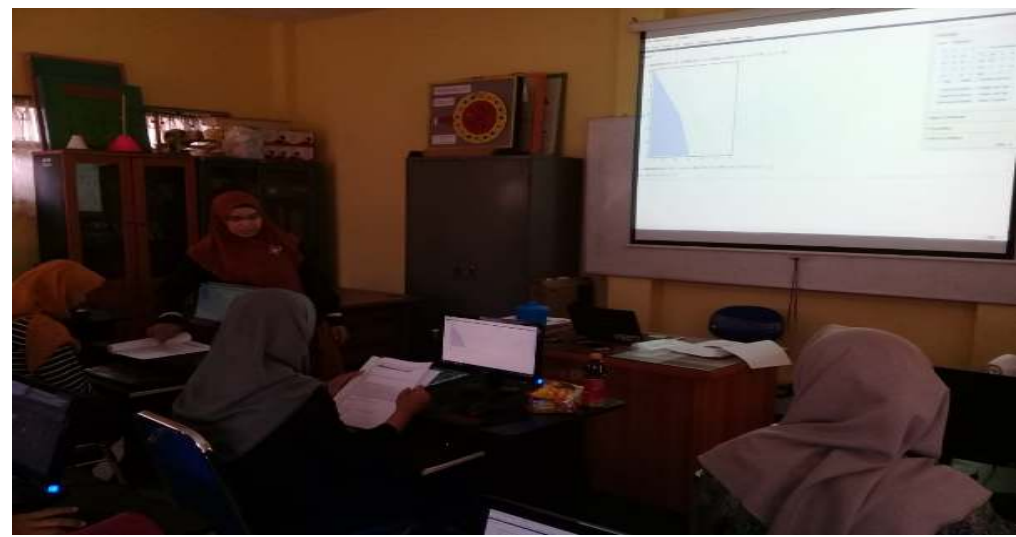

\section{Gambar 5. Pemberian Materi Penggunaan Software Wolfram}

Pada kegiatan ini dibahas juga mengenai software Wolfram mathematica dengan uraian materi sebagai berikut:

- Software waolfram software wolfram mathematica merupakan suatu sistem aljabar komputer (CAS, Computer Algebra System) yang mengintegrasikan kemampuan komputasi (simbolik, numerik), visualisasi (grafik), bahasa pemprograman, dan pengolahan kata (word processing) ke dalam suatu lingkungan yang sudah digunakan. Software wolfram mathematica merupakan software aplikasi buatan Wolfram Research yang handal dengan fasilitas terintegrasi lengkap untuk menyelesaikan beragam masalah matematika. Dengan Software wolfram mathematica kita akan merasakan sebuah revolusi pada peran dan praktik matematika yang dengannya beragam kasus matematika, dari masalah yang paling sederhana hingga perhitungan yang paling rumit, dapat diselesaikan dengan mudah, ringkas, cepat dan tepat. Software wolfram mathematica menyediakan fasilitas lengkap untuk melaksanakan semua komputasi matematika tersebut dalam suatu lingkungan kerja yang terintegrasi. Dalam lingkungan kerja yang demikian maka kita dapat melaksanakan beragam perhitungan matematika, seperti perhitungan aritmatika, perhitungan aljabar, perhitungan dan operasi simbolik dalam aljabar matriks, aljabar linear, linear programming, 
metode numerik, teori bilangan, matematika diskrit, kalkulus, transformasi laplace, transformasi fourier, transformasi-z, statistika, geometri, pemodelan matematika dan simulasi, dan lain-lain.

- Software wolfram mathematica juga memiliki fasilitas lengkap untuk membuat beragam grafik. Kita dapat membuat grafik fungsi aljabar, fungsi transenden, fungsi parametrik dan fungsi implisit, fungsi polar, kurva kontur, skaterplot, beragam grafik permukaan dimensi tiga, grafik medan vektor dimensi dua dan dimensi tiga, grafik animasi, diagram batang, diagram lingkaran dan lain-lain. Kini Software wolfram mathematica merupakan salah satu software pilihan dalam pendidikan, penelitian, bisnis dan sebagainya. Untuk pengoperasiannya, aplikasi ini mempunyai tampilan yang interaktif dengan tiga sistem pengoperasian yang mudah. Tampilan software wolfram mathematica pada jendela awalnya disajikan pada Gambar 6.

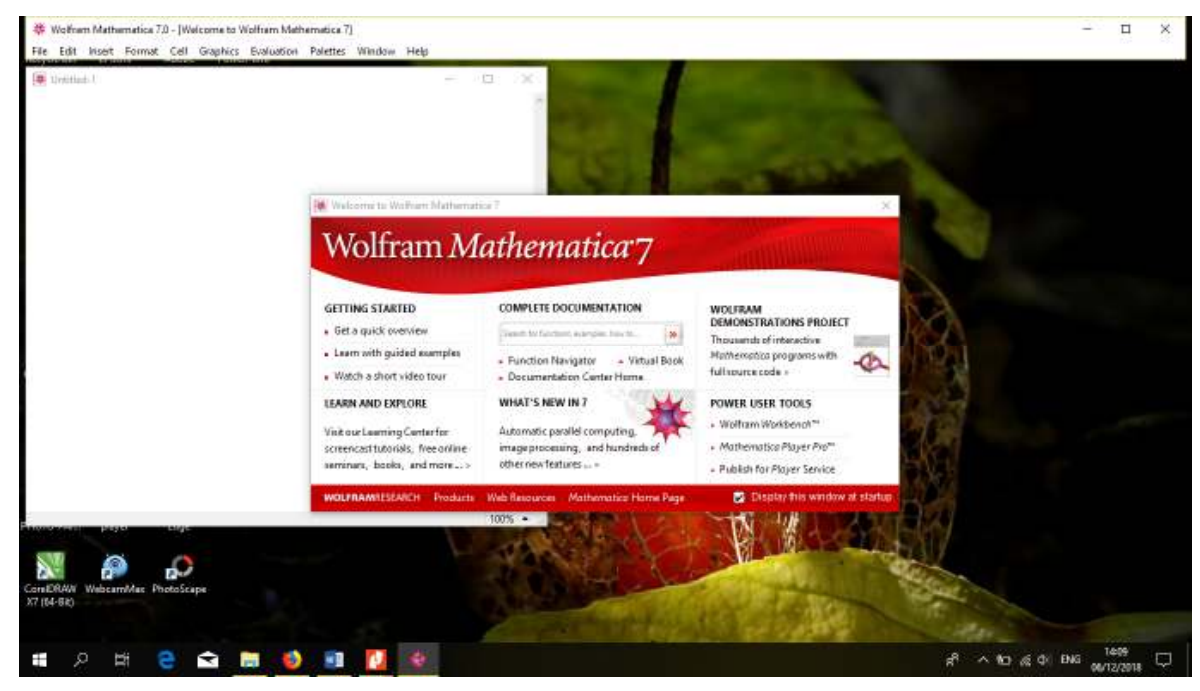

Gambar 6. Tampilan Jendela Awal Software Wolfram Mathematica

Kegiatan siswa pada kegatan penyuluhan ini disajikan pada Gambar 7, 8 dan 9.

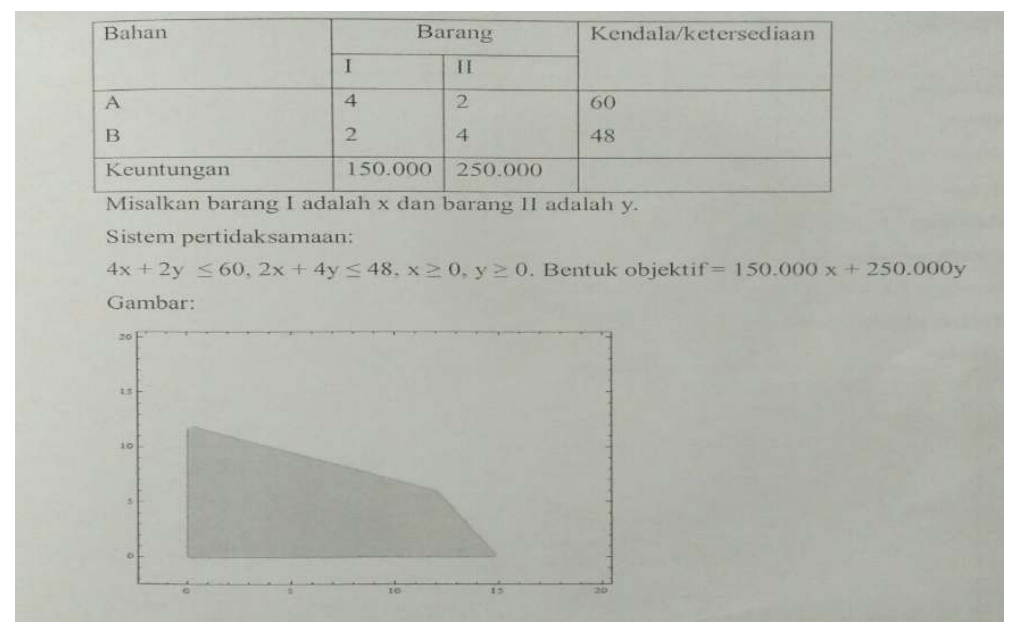

Gambar 7. Hasil Pekerjaan Siswa 


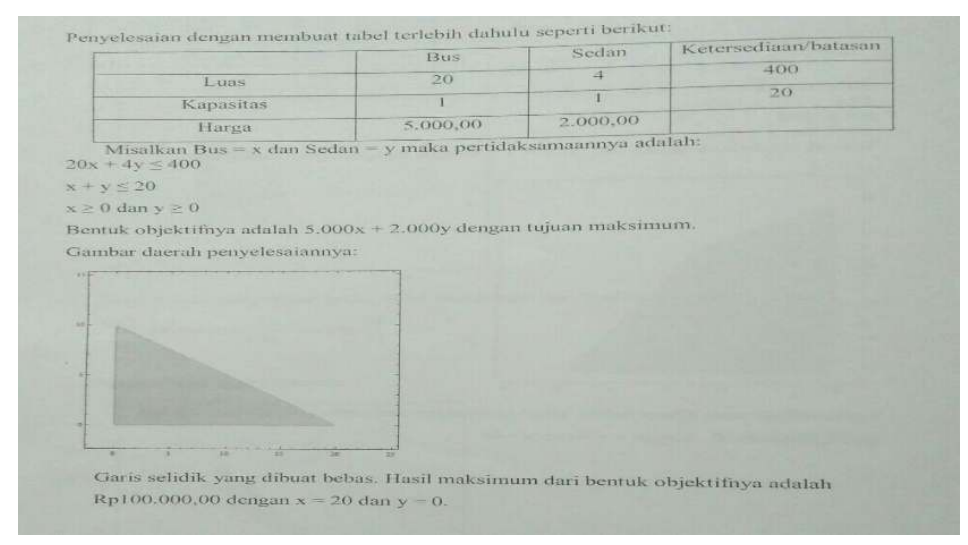

Gambar 8. Hasil Pekerjaan Siswa

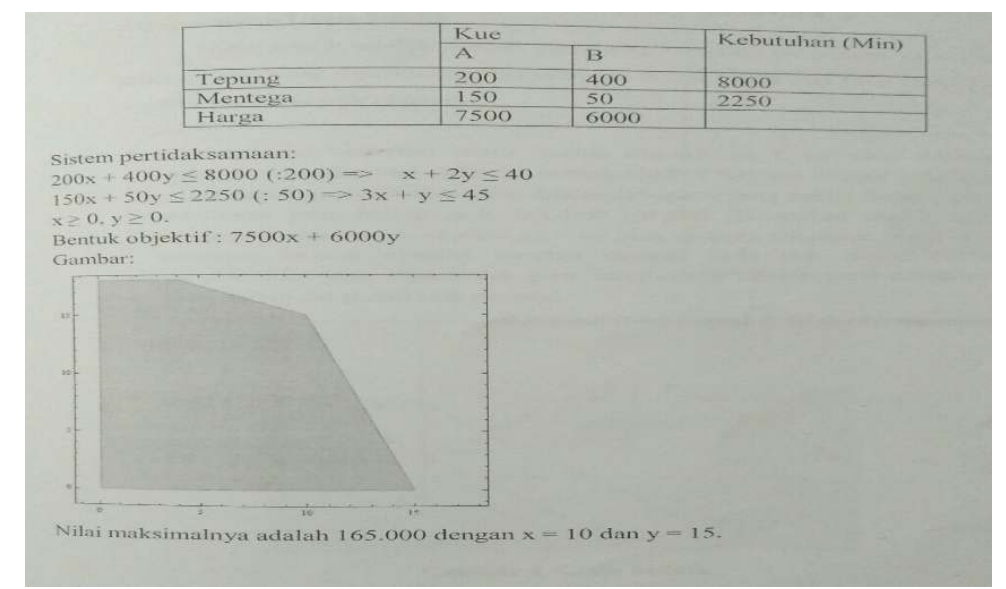

Gambar 9. Hasil Pekerjaan Siswa

Di akhir kegiatan, siswa diwawancara terlebih dahulu mengenai tanggapannya pada kegiatan pengabdian ini. Hasil wawancara siswa disajikan dalam bentuk rangkuman berikut ini:

1. Siswa merasa senang menjadi kader pada kegiatan pengabdian ini;

2. Siswa merasa termotivasi untuk berwirausaha agar dapat menghasilkan uang dari usaha sendiri;

3. Siswa merasa tertarik untuk segera berwirausaha;

4. Siswa merasa terbantu dalam hal penguasaannya terhadap materi Program Linear yang menjadi lebih paham dari sebelumnya;

5. Siswa merasa senang mempelajari software wolfram mathematica;

6. Siswa merasa tertarik untuk memperdalam penggunaan software wolfram mathematica;

7. Siswa merasa terbantu dalam menyelesaikan permasalahan Program Linear dengan adanya software wolfram mathematica.

Berdasarkan hasil wawancara tersebut, maka disimpulkan bahwa kegiatan ini memberikan manfaat yang banyak bagi siswa sebagai pelajar juga sebagai generasi muda yang 
harus siap berkompetisi kedepannya dalam mendapat penghasilan yang layak untuk membiayai kehidupan mereka kelak.

\section{KESIMPULAN DAN SARAN}

Kegiatan pengabdian ini memiliki kesimpulan bahwa siswa merasakan banyak manfaat dari kegiatan penyuluhan yang telah dilaksanakan diantaranya siswa termotivasi untuk berwirausaha, siswa merasa terbantu dalam hal penguasaannya terhadap materi Program Linear yang menjadi lebih paham dari sebelumnya, dan siswa merasa terbantu dalam menyelesaikan permasalahan Program Linear dengan adanya software wolfram mathematica.

Berlandaskan kesimpulan dan rangkaian kegiatan pengabdian ini, maka direkomendasikan untuk pengabdi selanjutnya menggunakan software yang dapat dimanfaatkan sebagai alat bantu siswa dalam menguasai materi pelajaran yang ada di sekolah sekaligus memotivasi siswa untuk memiliki bekal keterampilan hidup yang kelak dapat dimanfaatkan siswa.

\section{UCAPAN TERIMA KASIH}

Pengabdi mengucapkan terima kasih kepada Lembaga Penelitian dan Pengabdian kepada Masyarakat (LPPM) Universitas Galuh yang telah membiayai kegiatan ini sehingga dapat terlaksanan dengan baik. Ucapat terima kasih juga pengabdi sampaikan kepada siswa SMAN 1 Baregbeg yang telah menjadi kader kegiatan ini.

\section{DAFTAR PUSTAKA}

Bygrave, William D. 1994. The portable MBA in enterprenership. JhonWilley \& Sons, Inc. NewYork.

Kristanto HC, R Heru. 2009. Kewirausahaan Enterpreneurship Pendekatan Manajemen dan Praktik. Cet. I. Yogyakarta: Graha Ilmu.

Nugroho, A.A, Lukman, H \& Noviana, D.R. 2015. Efektifitas Penggunaan Bahan Ajar Berbasis Wolfram Software wolfram mathematica pada Mata Kuliah Aljabar Linier. Jurnal Euclid, 3(1): 411-422.

Kholidah, Siti. 2018. Faktor-faktor Kesuksesan Menjadi Enterpreneur. Skripsi. Universitas Lampung.

Sunaryo, Y. gan Fatimah, A.T. 2018. Program Linear dengan Pendekatan Kontekstual pada Model Pembelajaran Scaffolding. Ciamis: Tsaqiva Publishing.

Sunaryo, Y. dan Nuraida, I. 2018. Mengembangkan Kemampuan Pemahaman Matematis dan Self-Confidence Siswa Melalui Model Pembelajaran Hybrid Tipe Traditional ClasessReal Workshop. Jurnal Siliwangi Seri Pendidikan, 4(1): 28-32. 